\title{
PELAKSANAAN PEMBELAJARAN REMEDIAL MATA PELAJARAN KIMIA
}

\author{
P. N. Apriliani ${ }^{1}$, I. K. Sudiana ${ }^{2}$, N. M. Wiratini ${ }^{3}$ \\ Universitas Pendidikan Ganesha \\ Singaraja, Indonesia \\ e-mail: niaapriliani034@gmail.com, sudi.ana@undiksha.ac.id,
}

\begin{abstract}
Abstrak
Penelitian ini bertujuan untuk mendeskripsikan dan menjelaskan pelaksanaan pembelajaran remedial mata pelajaran kimia di SMA Negeri 2 Singaraja. Penelitian ini adalah jenis penelitian fenomenologi dengan pendekatan kualitatif. Subjek dalam penelitian ini adalah guru kimia, wakil kepala sekolah bidang kurikulum dan siswa kelas X dan XI MIPA. Metode pengumpulan data pada penelitian ini adalah observasi, wawancara dan studi dokumen. Aktivitas yang diteliti terkait pelaksanaan pembelajaran remedial kimia. Teknik keabsahan data dalam penelitian ini menggunakan triangulasi sumber dan metode. Data dianalisis menggunakan teknik kualitatif deskriptif. Hasil penelitian ini menunjukkan bahwa (1) guru kimia menyusun perencanaan pembelajaran remedial dengan menentukan waktu, metode, dan tujuan pembelajaran remedial kimia, (2) pelaksanaan pembelajaran remedial kimia dilaksanakan pada penilaian harian (PH) dan penilaian akhir tahun (PAT) sedangkan pada penilaian tengah semester (PTS) tidak dilaksanakan, dan (3) penilaian pembelajaran remedial yang diberikan kepada siswa setelah mengikuti remedial pada PH dan PAT tidak melebihi nilai KKM yang telah ditetapkan.
\end{abstract}

Kata kunci: evaluasi hasil belajar, KKM, pembelajaran remedial

\begin{abstract}
This study aimed to describe and explain the implementation of chemistry subject of remedial learning in SMA Negeri 2 Singaraja. This research was a type of phenomenological research in which it belong to a qualitative approach. The subjects in this study were chemistry teachers, vice principals in the curriculum field and students of class X and XI MIPA. The data collection methods which used in this study were observation, interviews and document studies. The technique of checking the validity of the data in this study used source and method of triangulation. The data of this research were analyzed using descriptive qualitative techniques. The results of this study indicated that, (1) the chemistry teacher prepared the remedial learning plan by determining the time, method and purpose of the remedial learning chemistry, (2) the implementation of chemical remedial learning carried out on daily assessment $(\mathrm{PH})$ and final assessment (PAT) while in the middle test (PTS) is not implemented, and (3) the assessment of remedial learning obtained by students after participating in remedial which did not exceed the passing grade criteria (KKM) score that has been set.
\end{abstract}

Keywords: evaluation of learning outcomes, KKM, remedial learning 


\section{PENDAHULUAN}

Kompetensi Dasar (KD) adalah pengetahuan, keterampilan, dan sikap minimal yang harus dicapai atau dimiliki oleh seorang peserta didik untuk menunjukkan bahwa siswa tersebut telah mampu menguasai standar kompetensi yang telah ditetapkan. Tercapainya KD diperlukan sebagai kriteria atau tolak ukur tercapainya Kriteria Ketuntasan Minimal (KKM) oleh guru dan/atau satuan pendidikan sebagai acuan untuk menentukan tindakan lanjutan, yaitu dilakukan pengayaan bagi peserta didik yang mencapai ketuntasan atau mengulang pembelajaran bagi peserta didik yang belum mencapai ketuntasan dalam hal ini peserta didik mengikuti kegiatan pembelajaran remedial.

Pembelajaran remedial merupakan suatu rancangan pembelajaran ulang yang dikenakan bagi peserta didik yang gagal menguasai suatu KD yang ditargetkan (Kemendiknas, 2010). Berdasarkan fungsinya pembelajaran remedial memiliki posisi yang sangat penting, remedial dapat dijadikan penyelesaian kewajiban guru untuk menghadirkan dan pemenuhan hak siswa untuk memeroleh pendidikan yang bermutu dengan pelayanan yang sesuai dengan bakat minat dan kemampuan, dan menyelesaikan program pendidikan dengan kecepatan masing-masing serta tidak menyimpang dari ketentuan batas waktu yang ditetapkan (UU No. 20 Tahun 2003).

Menurut Juknis Pembelajaran Tuntas, Remedial, dan Pengayaan di SMA dari Direktorat Pembina SMA tahun 2010 bahwa bentuk implementasi pembelajaran remedial dapat dilakukan dengan pemberian pembelajaran ulang dengan metode dan media yang berbeda jika jumlah peserta yang mengikuti remedial lebih dari $50 \%$; pemberian bimbingan secara khusus, misalnya bimbingan perorangan jika jumlah peserta didik yang mengikuti remedial maksimal $20 \%$; pemberian tugas-tugas kelompok jika jumlah peserta yang mengikuti remedial lebih dari $20 \%$ tetapi kurang dari $50 \%$ dan pemanfaatan tutor teman sebaya. Semua pembelajaran remedial yang dilakukan diakhiri dengan tes ulang dan dilaksanakan di luar jam tatap muka.

Berdasarkan fakta di lapangan pelaksanaan pembelajaran remedial tidak seutuhnya dilakukan oleh guru atau satuan pendidikan di sekolah. Hal ini terbukti dari hasil evaluasi pelaksanaan program remedial pada kegiatan Bimbingan Teknis (Bimtek) KTSP tahun 2008 dan 2009 yang dilaksanakan oleh Direktorat Pembinaan SMA ditemukan bahwa pada umumnya guru telah melaksanakan program remedial tetapi tidak melalui analisis hasil belajar peserta didik. Kemudian berdasarkan hasil evaluasi kegiatan pendampingan kurikulum 2013 yang dilaksanakan oleh lembaga yang sama ditemukan bahwa pada umumnya pendidik melaksanakan remedial berupa tes ulang tanpa melakukan perbaikan proses pembelajaran berdasarkan analisis hasil belajar peserta didik. Selain itu, sering ditemukan guru memberikan tes ulang dengan soal-soal yang sama terhadap semua peserta didik yang belum mencapai ketuntasan tanpa melakukan pembelajaran ulang, tugas bimbingan, pemanfaatan teman sejawat, dan tanpa memperhatikan indikator yang belum dikuasai oleh masing-masing peserta didik (Direktorat Pembinaan SMA, 2010).

SMA Negeri 2 Singaraja adalah salah satu sekolah yang terdapat di kota Singaraja yang terakreditasi A dengan artian bahwa SMA Negeri 2 Singaraja telah mengacu pada 8 (delapan) standar penilaian pendidikan salah satunya adalah standar proses. Standar proses mencakup perencanaan proses pembelajaran, pelaksanaan proses pembelajaran, penilaian hasil belajar, dan pengawasan proses pembelajaran. Meskipun SMA Negeri 2 Singaraja terakreditasi A, namun dalam pelaksanaan proses pembelajaran masih belum efektif dan masih menemui kendala khususnya dalam pelaksanaan pembelajaran remedial. Pelaksanaan pembelajaran remedial seolah-olah hanya sekedar sebagai syarat agar nilai siswa mencapai KKM. Hal ini semakin terlihat dalam pelaksanaan pembelajaran remedial mata pelajaran kimia yang terkendala dengan waktu dan teknik pelaksanaannya.

Berdasarkan studi pendahuluan yang dilakukan peneliti di SMA Negeri 2 Singaraja dengan teknik wawancara kepada guru kimia menunjukan bahwa pembelajaran remedial kimia ditujukan untuk siswa yang belum mencapai ketuntasan atau belum mencapai KKM pada mata pelajaran kimia. KKM mata pelajaran kimia di SMA Negeri 2 Singaraja adalah 68. Hal tersebut dapat dicermati dari evaluasi hasil belajar yang diperoleh siswa pada mata pelajaran kimia. Siswa yang memeroleh evaluasi hasil belajar di bawah KKM pada penilaian harian $(\mathrm{PH})$, penilaian tengah semester (PTS) dan penilaian akhir tahun (PAT) akan mengikuti kegiatan pembelajaran remedial. Namun, berdasarkan hasil observasi yang dilakukan oleh peneliti menunjukkan bahwa pembelajaran remedial pada PH dan PAT dilakukan dengan mengerjakan tes ulang yang sama pada pertemuan selanjutnya tanpa guru melaksanakan pembelajaran dengan metode dan media yang berbeda pada materi yang sama terkait kompetensi dasar atau indikator yang belum dicapai oleh siswa. Sedangkan, pelaksanaan pembelajaran remedial pada PTS tidak dilaksanakan. Temuan lain juga ditemukan terkait waktu pelaksanaan remedial yang mana pelaksanaan remedial di SMA Negeri 2 Singaraja masih dilaksanakan pada jam efektif mengajar hal ini bertentangan 
dengan aturan yang seharusnya. Idealnya, pelaksanaan pembelajaran remedial dilaksanakan dengan pemberian materi ulang terakait indikator atau kompetensi dasar yang belum tuntas di luar jam efektif mengajar. Pembelajaran remedial terus diberikan sampai memeroleh nilai KKM.

Berdasarkan studi dokumen yang dilakukan dengan mencermati hasil $\mathrm{PH}$ mata pelajaran kimia, persentase siswa yang mengikuti remedial kimia pada masing-masing kelas X dan XI MIPA tidak sama, namun metode pembelajaran remedial yang digunakan guru kimia untuk memberikan remedial dibuat sama, yaitu mengerjakan soal tes sebelumnya. Hal ini tentunya bertentangan dengan yang dijelaskan dalam Juknis Pembelajaran Tuntas, Remedial, dan Pengayaan di SMA dari Direktorat Pembina SMA tahun 2010. Idealnya, implementasi pembelajaran remedial dengan persentase jumlah siswa yang mengikuti remedial berbeda maka metode pembelajaran remedial yang digunakan harus berbeda.

Berkaitan dengan beberapa penelitian yang telah dipaparkan dan studi pendahuluan yang telah dilakukan dapat menunjukkan bahwa kegiatan pembelajaran remedial yang selama ini berjalan belum sesuai dengan standar yang ada. Pembelajaran remedial hanya dilakukan sebagai formalitas atau legalitas untuk meluluskan siswa yang tidak mencapai KKM bukan untuk memenuhi KD yang belum dipahami oleh peserta didik. Jika hal ini masih dilakukan oleh semua guru khususnya guru kimia maka dapat dipastikan bahwa tingkat ketuntasan siswa bukan cerminan ketuntasan kompetensi siswa yang sebenarnya.

Berdasarkan uraian di atas maka dipandang perlu melakukan penelitian untuk mengetahui pelaksanaan pembelajaran remedial mata pelajaran kimia di SMA Negeri 2 Singaraja. Oleh karena itu, penulis telah melaksanakan penelitian yang berjudul "Pelaksanaan Pembelajaran Remedial Mata Pelajaran Kimia di SMA Negeri 2 Singaraja". Melalui penelitian ini diharapkan dapat memberi gambaran keadaan sebenarnya tentang pelaksanaan pembelajaran remedial oleh guru kimia di SMA Negeri 2 Singaraja sehingga dapat digunakan sebagai refleksi untuk memperbaiki kualitas pembelajaran mata pelajaran kimia pada khususnya dan pendidikan di SMA Negeri 2 Singaraja pada umumnya.

\section{METODE}

Penelitian ini adalah jenis penelitian fenomenologi dengan pendekatan kualitatif. Lokasi penelitian dilakukan di SMA Negeri 2 Singaraja dengan status akreditasi A, yang beralamat di Jalan Srikandi No. 6 Baktiseraga, Kecamatan Buleleng, Kabupaten Buleleng. Subjek yang diteliti adalah guru kimia, wakil kepala sekolah bidang kurikulum dan siswa kelas X dan XI MIPA. Aktivitas yang diteliti dalam penelitian ini adalah terkait dengan pelaksanaan pembelajaran remedial kimia di SMA Negeri 2 Singaraja. Data terkait pelaksanaan pembelajaran remedial dikumpulkan melalui teknik observasi, teknik studi dokumen dan teknik wawancara. Data dianalisis menggunakan teknik kualitatif deskriptif. Teknik pemeriksaan keabsahan data dalam penelitian ini menggunakan teknik triangulasi sumber dan metode. Ketika melakukan triangulasi data dengan teknik wawancara maka perlu dilakukan member check. Member check dilakukan kepada guru kimia, wakasek kurikulum, dan siswa kelas X dan XI MIPA.

\section{HASIL DAN PEMBAHASAN}

Berdasarkan hasil analisis data yang dilaksanakan oleh peneliti, pelaksanaan pembelajaran remedial yang dilaksanakan oleh guru kimia di SMA Negeri 2 Singaraja terdapat 3 proses yang diamati oleh peneliti diantaranya, yaitu; perencanaan, pelaksanaan, dan penilaian pembelajaran remedial kimia pada mata pelajaran kimia.

1.Perencanaan Pembelajaran Remedial Mata Pelajaran Kimia

Guru kimia sebelum membuat perencanaan terkait metode yang digunakan dalam pembelajaran remedial maka guru melakukan diagnosis kesulitan belajar dengan mengidentifikasi siswa melalui analisis nilai evaluasi sebelumnya dan melokalisasi letak kesulitan dengan melihat hasil pekerjaan siswa (Sugihartono, dkk., 2007). Hal tersebut telah dilakukan oleh guru kimia di SMA Negeri 2 Singaraja yang mana guru telah mengidentifikasi dan melokalisasi letak kesulitan dengan mengecek pekerjaan siswa pada penilaian harian lalu dikelompokkan siswa yang mendapat nilai dibawah KKM untuk mengikuti remedial. Penelitian ini hampir sejalan dengan penelitian yang dilakukan oleh Kurnia (2016) bahwa dalam perencanaan pembelajaran remedial sebelumnya guru mendiagnosis kesulitan belajar dengan mengidentifikasi siswa melalui analisis nilai evaluasi sebelumnya, melokalisasi letak kesulitan dengan melihat hasil pekerjaan siswa, dan menentukan penyebab kesulitan belajar siswa. Setelah guru mengetahui jumlah siswa yang remedial maka guru dapat menyusun perencanaan remedial yang akan dilaksanakan.

Program pembelajaran remedial sebelumnya sudah tercantum dalam RPP yang disusun berdasarkan hasil penilaian otentik yang digunakan oleh guru sesuai dengan Permendikbud No 22 
tahun 2016. Sebelum guru memberikan remedial, guru kimia sebelumnya harus telah menyusun perencanaan terkait pelaksanaan remedial yang akan dilaksanakan, namun berdasarkan hasil wawancara dan studi dokumen yang dilakukan penyusunan perencanaan pembelajaran remedial masih kurang optimal. Terdapat beberapa hal yang diperhatikan guru kimia di SMA Negeri 2 Singaraja dalam menyusun perencanaan pembelajaran remedial, yaitu terkait waktu pelaksanaan pembelajaran remedial, metode yang digunakan guru dalam pembelajaran remedial dan tujuan dari pembelajaran kimia itu sendiri. Beberapa rancangan pelaksanaan pembelajaran remedial yang disampaikan guru kimia telah sesuai dengan teori yang dipaparkan oleh Syah (2008) yang menjelaskan bahwa dalam menyusun program pengajaran perbaikan sebelumnya guru perlu menetapkan hal-hal yaitu; (1) tujuan pengajaran remedial, (2) Materi pengajaran remedial, (3) metode pengajaran remedial, (4) alokasi waktu pengajaran remedial, dan (5) evaluasi kemajuan siswa setelah mengikuti program pengajaran remedial. Penetapan langkah tersebut dilakukan sebagai pedoman bagi guru untuk mempermudah pelaksanaan remedial yang tepat sehingga fungsi remedial dapat dimanfaatkan secara maksimal oleh siswa dan membantu guru dalam upaya ketercapaian KKM oleh siswa.

Data yang diperoleh peneliti melalui studi dokumen pada RPP yang dibuat oleh guru menunjukkan bahwa guru kimia telah membuat perencanaan terkait metode yang akan digunakan. Metode yang digunakan guru dalam melaksanakan pembelajaran remedial, yaitu pembelajaran yang berbeda dengan pemberian materi ulang terkait indikator dari kompetensi dasar yang belum dipahami oleh siswa dan tujuan pembelajaran remedial yang direncanakan oleh guru kimia juga disesuaikan dengan indikator dari kompetensi dasar yang belum dipahami oleh siswa. Selain itu, pada RPP juga tercantum terkait evaluasi pembelajaran remedial untuk mengukur sejauh mana perubahan siswa setelah mengikuti pembelajaran remedial.

Berdasarkan perencanaan yang telah disusun oleh guru kimia terdapat hambatan yang dialami oleh guru dalam merencanakan pembelajaran remedial, yaitu menentukan alokasi waktu terkait perencanaan yang dibuat. Pelaksanaan pembelajaran remedial seharusnya dilaksanakan di luar jam pelajaran reguler agar tidak mengganggu materi pelajaran selanjutnya namun, mengingat pada sore hari telah dijadwalkan kegiatan ekstrakurikuler maka pembelajaran remedial mata pelajaran kimia dilaksanakan pada jam pelajaran reguler ketika ada jadwal pelajaran kimia yang disesuaikan dengan situasi dan kondisi dari sekolah yang bersangkutan.

\section{Pelaksanaan Pembelajaran Remedial Mata Pelajaran Kimia}

Pembelajaran remedial yang dilaksanakan di SMA Negeri 2 Singaraja dilaksanakan setelah siswa selesai melaksanakan evaluasi penilaian harian (PH), Penilaian Tengah Semester (PTS), dan Penilaian Akhir Tahun (PAT).

a. Pelaksanaan Pembelajaran Remedial Pada Penilaian Harian (PH)

Pembelajaran remedial mata pelajaran kimia di SMA Negeri 2 Singaraja dilaksanakan setelah siswa melaksanakan evaluasi hasil belajar pada pokok bahasan/topik kimia tertentu yang dianggap sebagai penilaian harian $(\mathrm{PH})$. Berdasarkan studi dokumen yang dilakukan oleh peneliti diperoleh data siswa yang mengikuti remedial pada topik kimia tertentu, yaitu untuk kelas X MIPA pada PH 1 topik larutan elektrolit dan non elektrolit dan $\mathrm{PH} 2$ topik reaksi reduksi dan oksidasi serta tata nama senyawa sedangkan untuk kelas XI MIPA pada PH 1 topik asam basa dan PH 2 topik hidrolisis garam pada tahun ajaran 2018/2019 sebagai berikut.

Tabel. 1 Sebaran Ketuntasan Siswa Kelas X MIPA

Pada PH 1 dan PH 2 Mata Pelajaran Kimia Tahun ajaran 2018/2019

\begin{tabular}{|c|c|c|c|c|c|c|}
\hline \multirow{5}{*}{ Kelas } & \multicolumn{2}{|c|}{$\mathrm{PH} 1$} & \multicolumn{4}{|c|}{$\mathrm{PH} 2$} \\
\hline & Jumlah & Jumlah & & Jumlah & Jumlah & \\
\hline & Siswa & Siswa & (\%) Siswa & Siswa & Siswa & (\%) Siswa \\
\hline & Tuntas & Belum & Remedial & Tuntas & Belum & Remedial \\
\hline & (orang) & $\begin{array}{l}\text { Tuntas } \\
\text { (orang) }\end{array}$ & & (orang) & $\begin{array}{l}\text { Tuntas } \\
\text { (orang }\end{array}$ & \\
\hline X MIPA 1 & 20 & 14 & 41,18 & 22 & 12 & 35,29 \\
\hline X MIPA 2 & 24 & 10 & 29,41 & 11 & 23 & 67,65 \\
\hline X MIPA 3 & 9 & 25 & 73,52 & 23 & 11 & 32,35 \\
\hline X MIPA4 & 9 & 25 & 73,52 & 1 & 33 & 97,06 \\
\hline X MIPA 5 & 26 & 10 & 27,70 & 7 & 29 & 80,56 \\
\hline X MIPA 6 & 16 & 17 & 51,51 & 23 & 10 & 30,30 \\
\hline X MIPA 7 & 8 & 23 & 71,85 & 0 & 31 & 100 \\
\hline
\end{tabular}


Sesuai dengan Tabel. 1 maka metode pembelajaran remedial yang idealnya digunakan oleh guru berdasarkan persentase jumlah siswa yang mengikuti remedial pada PH 1 topik larutan elektrolit dan non elektroli, yaitu pada kelas X MIPA 1, X MIPA 2 dan X MIPA 5 dengan metode pemberian tugas-tugas kelompok karena jumlah peserta yang mengikuti remedial lebih dari $20 \%$ tetapi kurang dari 50\% dan kelas X MIPA 3, X MIPA 4, X MIPA 6 dan X MIPA 7 dengan pemberian pembelajaran ulang dengan metode dan media yang berbeda karena jumlah peserta yang mengikuti remedial lebih dari 50\%. Sedangkan $\mathrm{PH} 2$ pada topik reaksi reduksi dan oksidasi serta tata nama senyawa, yaitu kelas X MIPA 1, X MIPA 3, X MIPA 6 dengan metode pemberian tugastugas kelompok karena jumlah peserta yang mengikuti remedial lebih dari $20 \%$ tetapi kurang dari $50 \%$ dan kelas X MIPA 2, X MIPA 4, X MIPA 5, dan X MIPA 7 dengan pemberian pembelajaran ulang dengan metode dan media yang berbeda karena jumlah peserta yang mengikuti remedial lebih dari $50 \%$.

Tabel. 2 Sebaran Ketuntasan Siswa Kelas XI MIPA Pada PH 1 dan PH 2 Mata Pelajaran Kimia Tahun ajaran 2018/2019

\begin{tabular}{|c|c|c|c|c|c|c|}
\hline \multirow{5}{*}{ Kelas } & \multicolumn{2}{|c|}{$\mathrm{PH} 1$} & \multicolumn{4}{|c|}{$\mathrm{PH} 2$} \\
\hline & Jumlah & Jumlah & & Jumlah & Jumlah & \\
\hline & Siswa & Siswa & (\%) Siswa & Siswa & Siswa & (\%) Siswa \\
\hline & Tuntas & Belum & Remedial & Tuntas & Belum & Remedial \\
\hline & (orang) & $\begin{array}{l}\text { Tuntas } \\
\text { (orang) }\end{array}$ & & (orang) & $\begin{array}{l}\text { Tuntas } \\
\text { (orang) }\end{array}$ & \\
\hline XI MIPA 1 & 18 & 14 & 43,75 & 20 & 12 & 37,50 \\
\hline XI MIPA 2 & 21 & 13 & 38,23 & 24 & 10 & 29,41 \\
\hline XI MIPA 3 & 22 & 10 & 45,45 & 24 & 8 & 25,00 \\
\hline XI MIPA 4 & 13 & 17 & 56,67 & 16 & 14 & 41,17 \\
\hline XI MIPA 5 & 8 & 26 & 76,47 & 12 & 22 & 64,71 \\
\hline
\end{tabular}

Sesuai dengan Tabel. 2 maka metode pembelajaran remedial yang idealnya digunakan oleh guru berdasarkan persentase jumlah siswa yang mengikuti remedial pada $\mathrm{PH} 1$ topik asam basa, yaitu pada kelas XI MIPA 1, X MIPA 2 dan X MIPA 3 dengan metode pemberian tugas-tugas kelompok karena jumlah peserta yang mengikuti remedial lebih dari $20 \%$ tetapi kurang dari $50 \%$ dan kelas X MIPA 4 dan X MIPA 5 dengan pemberian pembelajaran ulang dengan metode dan media yang berbeda karena jumlah peserta yang mengikuti remedial lebih dari $50 \%$. Sedangkan PH 2 pada topik hidrolisis garam, yaitu kelas X MIPA 1, X MIPA 2, X MIPA 3 dan MIPA 4 dengan metode pemberian tugas-tugas kelompok karena jumlah peserta yang mengikuti remedial lebih dari $20 \%$ tetapi kurang dari $50 \%$ dan kelas X MIPA 5 dengan pemberian pembelajaran ulang dengan metode dan media yang berbeda karena jumlah peserta yang mengikuti remedial lebih dari $50 \%$.

Berdasarkan studi dokumen pada Tabel. 1 dan Tabel. 2 bahwa jumlah siswa yang mengikuti remedial di kelas $X$ dan XI MIPA pada mata pelajaran kimia untuk tahun ajaran 2018/2019 menunjukkan persentase yang berbeda pada PH 1 dan PH 2 di kelas X dan XI MIPA. Idealnya, persentase yang berbeda menunjukkan implementasi pembelajaran remedial yang dilaksanakan juga berbeda. Namun, berdasarkan fakta di lapangan pelaksanaan pembelajaran remedial yang dilaksanakan di SMA Negeri 2 Singaraja dilaksanakan sama, yaitu dengan metode pemberian tugas secara individu berupa pengerjaan soal-soal pada LKS atau pengerjaan kembali soal penilaian harian sebelumnya tanpa memperhatikan indikator yang belum dipahami oleh siswa serta tanpa memperhatikan persentase siswa yang mengikuti kegiatan remedial. Sehingga remedial yang diberikan tidak menguji indikator yang tidak tuntas saja, melainkan seluruh indikator diuji kembali karena guru tidak melakukan analisis hasil penilaian harian. Hal tersebut sejalan dengan penelitian yang dilakukan oleh Irnidayanti dan Puspitaningrum (2013) bahwa dalam pemberian remedial soal tes remedial yang diberikan tidak menguji indikator yang tidak tuntas saja, melainkan seluruh indikator diuji kembali karena guru tidak melakukan analisis pada tes yang diberikan. Guru tidak melakukan analisis pada tes tersebut karena guru disibukkan dengan administrasi guru yang harus segera diselesaikan. Selain itu, ketika remedial guru tidak menggunakan metode dan media yang berbeda.

Terdapat hambatan terkait pelaksanaan remedial, yaitu (1) waktu pelaksanaan pembelajaran remedial kimia yang mana dilaksanakan pada pertemuan berikutnya ketika jam pelajaran reguler karena pada sore hari terdapat kegiatan ektrakurikuler yang mewajibkan semua peserta didik mengikuti kegiatan tersebut. Hal ini sejalan dengan penelitian yang dilakukan oleh Chitsa (2016) bahwa hambatan dalam pelaksanaan pembelajaran remedial adalah terkait waktu 
pelaksanaan dan kemampuan siswa yang berbeda-beda. (2) Padatnya beban mengajar guru dan materi kimia pada semester genap, apabila guru memberikan pembelajaran remedial dan dilaksanakan ketika jam pelajaran reguler maka guru akan terhambat untuk pemberian materi berikutnya karena terdapat beberapa siswa yang mengikuti remedial. Hal ini hampir sejalah dengan penelitian yang dilakukan oleh Kasran, dkk (2012) bahwa terdapat masalah yang teridentifikasi dalam pelaksanaan remedial, yaitu beban kerja guru, lingkungan belajar yang kurang kondusif dan kurangnya dukungan administrator sekolah berkontribusi dalam kegiatan tersebut. (3) Padatnya kalender pendidikan mencakup kegiatan sekolah dan waktu libur yang tidak terduga menyebabkan pembelajaran remedial tidak terlaksana sesuai perencanaan yang diprogramkan. Hal tersebut sejalan dengan penelitian Hermawati, dkk. (2018), terdapat faktor penghambat pelaksanaan remedial teaching, yaitu masalah waktu pelaksanaan. Pelaksanaan remedial teaching seharusnya dilaksanakan diluar jam pelajaran namun kesulitan menentukan waktu pelaksanaannya karena terhalang oleh waktu libur yang tidak terduga. Sehingga pelaksanaan pembelajaran remedial pada $\mathrm{PH}$ tidak dapat terlaksana sesuai petunjuk teknis pembelajaran remedial.

b. Pelaksanaan Pembelajaran Remedial Pada Penilaian Tengah Semester (PTS)

Pelaksanaan PTS dan remedial untuk PTS di SMA Negeri 2 Singaraja tidak dilaksanakan. PTS yang dilaksanakan di SMA Negeri 2 Singaraja hanya dilakukan dengan menjumlahkan hasil ulangan harian pada KD1 dan KD 2. Hasil penjumlahan hasil penilaian harian tersebut digunakan sebagai pelaporan Nilai Tengah Semester (NTS). Apabila setelah dilakukan penjumlahan hasil nilai ulangan harian pada KD1 dan KD2 masih terdapat siswa yang belum mencapai ketuntasan dan masih memperoleh nilai di bawah KKM, nilai tersebut akan tetap di kumpulkan pada guru BK sebagai bahan pertimbangan untuk pemanggilan siswa dan perbaikan siswa untuk tengah semester berikutnya. Remedial PTS tidak dilakukan karena guru kimia lebih memfokuskan siswa untuk mempersiapakan PAT. Apabila dilakukan PTS maka materi pada semester genap akan sulit terkejar sedangkan tuntutan PAT adalah semua materi di semester ganjil dan genap. Selain itu, kalender pendidikan di semester genap cukup padat, untuk menangulangi hal tersebut maka PTS hanya dilakukan dengan menggunakan nilai pada penilaian harian 1 dan penilaian harian 2 . Berdasarkan hal tersebut menujukkan bahwa pembelajaran remedial pada PTS tidak terlaksana sesuai dengan petunjuk teknis pembelajaran remedial.

c. Pelaksanaan Pembelajaran Remedial Pada Penilaian Akhir Tahun (PAT)

Pelaksanaan pembelajaran remedial pada PAT dilakukan apabila terdapat siswa memeroleh nilai PAT di bawah KKM yang telah ditetapkan, yaitu 68. Berdasarkan studi dokumen dan pencermatan hasil penilaian akhir tahun, diperoleh data bahwa terdapat siswa yang mendapatkan nilai dibawah KKM untuk mata pelajaran kimia di kelas X dan XI MIPA tahun ajaran 2018/2019 sehingga siswa tersebut harus mengikuti kegiatan remedial kimia. Berikut ini adalah data siswa yang mengikuti remedial kimia di kelas X dan XI MIPA tahun ajaran 2018/2019 yang diperoleh peneliti melalui studi dokumen.

Tabel. 3 Sebaran Ketuntasan Siswa Kelas X MIPA Pada Penilaian Akhir Tahun Mata Pelajaran Kimia Tahun Ajaran 2018/2019

\begin{tabular}{cccc}
\hline Kelas & $\begin{array}{c}\text { Jumlah Siswa } \\
\text { Belum Tuntas }\end{array}$ & $\begin{array}{c}\text { Jumlah Siswa } \\
\text { Tuntas }\end{array}$ & $\begin{array}{c}(\%) \text { Siswa Belum } \\
\text { Tuntas }\end{array}$ \\
\hline X MIPA 1 & 7 & 27 & 20,58 \\
X MIPA 2 & 31 & 3 & 91,17 \\
X MIPA 3 & 34 & 0 & 100 \\
X MIPA 4 & 31 & 2 & 96,87 \\
X MIPA 5 & 32 & 4 & 88,89 \\
X MIPA 6 & 25 & 8 & 75,76 \\
X MIPA 7 & 29 & 2 & 90,63 \\
\hline
\end{tabular}

Sesuai dengan Tabel. 3 maka metode pembelajaran remedial yang idealnya digunakan oleh guru berdasarkan persentase jumlah siswa yang mengikuti remedial pada PAT, yaitu pada kelas $X$ MIPA 1 dengan metode pemberian tugas-tugas kelompok karena jumlah peserta yang mengikuti remedial lebih dari $20 \%$ tetapi kurang dari $50 \%$ dan kelas X MIPA 2, X MIPA 3, X MIPA 4, X MIPA 5 , X MIPA 6 dan X MIPA 7 dengan pemberian pembelajaran ulang dengan metode dan media yang berbeda karena jumlah peserta yang mengikuti remedial lebih dari $50 \%$. 
Tabel 4. Sebaran Ketuntasan Siswa Kelas XI MIPA Pada Penilaian Akhir Tahun Mata Pelajaran Kimia Tahun Ajaran 2018/2019

\begin{tabular}{cccc}
\hline Kelas & $\begin{array}{c}\text { Jumlah Siswa } \\
\text { Belum Tuntas }\end{array}$ & $\begin{array}{c}\text { Jumlah Siswa } \\
\text { Tuntas }\end{array}$ & $\begin{array}{c}\text { (\%) Siswa Belum } \\
\text { Tuntas }\end{array}$ \\
\hline XI MIPA 1 & 32 & 0 & 100 \\
XI MIPA 2 & 36 & 0 & 100 \\
XI MIPA 3 & 32 & 0 & 100 \\
XI MIPA 4 & 31 & 0 & 100 \\
XI MIPA 5 & 34 & 0 & 100 \\
\hline
\end{tabular}

Sesuai dengan Tabel. 4 maka metode pembelajaran remedial yang idealnya digunakan oleh guru berdasarkan persentase jumlah siswa yang mengikuti remedial pada PAT, yaitu pada kelas XI MIPA 1, XI MIPA 2, XI MIPA 3, XI MIPA 4 dan XI MIPA 5 dengan pemberian pembelajaran ulang dengan metode dan media yang berbeda karena jumlah peserta yang mengikuti remedial lebih dari $50 \%$.

Berdasarkan hasil studi dokumen pada Tabel. 3 dan Tabel. 4 diperoleh jumlah dan persentase siswa yang mengikuti remedial di kelas X dan XI MIPA pada mata pelajaran kimia untuk tahun ajaran 2018/2019. Siswa yang mengikuti remedial kimia adalah siswa yang memeroleh nilai dibawah KKM mata pelajaran kimia, yaitu 68. Bagi siswa yang memeroleh nilai dibawah KKM, diberikan remedial oleh guru sebagai tindak lanjut terhadap penilaian. Bentuk remedial yang diberikan guru, yaitu berupa tugas individu mengerjakan soal PAT sebelumnya di rumah. Remedial pada PAT berbeda dengan remedial pada penilaian harian, yang mana remedial pada PAT dilakukan sebagai perbaikan terhadap nilai saja bukan berdasarkan pemahaman siswa. Hal tersebut sesuai dengan hasil penelitian yang dilaksanakan oleh Qibtiyah dan Maryatul (2017) yang menyatakan bahwa program remedial juga dilaksanakan setelah dilaksanakan penilaian akhir semester. Program remedial yang dilakukan pada waktu-waktu tersebut adalah untuk memperbaiki kesulitan belajar peserta didik dengan melihat pada materi mana peserta didik gagal. Akan tetapi, program remedial pada waktu tersebut biasanya cenderung hanya kepada perbaikan nilai agar mencapai KKM.

Pelaksanaan remedial pada PAT hanya dilakukan dengan pemberian tugas mengerjakan tes PAT sebelumnya tidak menguji indikator yang tidak tuntas saja melainkan semua indikator diuji kembali karena guru tidak melakukan analisis pada hasil tes PAT yang diperoleh siswa. Hal tersebut sejalan dengan penelitian Irnidayanti dan Puspitaningrum (2013) bahwa soal tes remedial yang diberikan tidak menguji indikator yang tidak tuntas saja, melainkan seluruh indikator diuji kembali karena guru tidak melakukan analisis pada tes yang diberikan. Hal tersebut terjadi karena jika dilihat dari ketersediaan waktu sudah tidak memungkinkan untuk memberikan materi ulang terkait indikator dari KD yang belum tuntas karena guru disibukkan dengan penginputan nilai pada rapor sehingga memerlukan waktu yang lebih intensif. Selain itu, jika siswa diberikan soal yang berbeda pada remedial PAT peluang siswa yang mengikuti remedial masih tetap banyak karena siswa tidak menyiapkan diri dengan baik untuk mengikuti remedial. Hal ini sejalan dengan penelitian yang dilakukan oleh Chitsa (2016) bahwa hambatan dalam pelaksanaan pembelajaran adalah terkait waktu pelaksanaan dan kemampuan siswa yang berbeda-beda. Sehingga pelaksanaan pembelajaran remedial pada PAT tidak dapat terlaksana sesuai dengan petunjuk teknis pembelajaran remedial.

\section{Penilaian Pembelajaran Remedial Mata pelajaran Kimia}

Setelah dilaksanakan kegiatan remedial maka diakhiri dengan penilaian untuk mengukur sejauh mana perubahan yang dialami siswa setelah mengikuti remedial. Remedial diberikan kepada siswa yang belum mencapai ketuntas atau nilainya dibawah KKM. Remedial diberikan berupa pengerjaan tugas LKS atau mengerjakan soal penilain sebelumnya. Bagi siswa yang belum mencapai ketuntas maka diperbolehkan melakukan perbaikan hingga batas akhir semester. Hal ini sesuai dengan Panduan Penilaian SMA Kurikulum 2013 menyatakan bahwa apabila setelah peserta didik melakukan pembelajaran remedial maka diakhiri dengan penilaian untuk melihat pencapaian peserta didik pada KD yang diremedial.

Idealnya, pembelajaran remedial difokuskan pada KD yang belum tuntas dan dapat diberikan berulang-ulang sampai mencapai KKM dengan waktu hingga batas akhir semester. Apabila hingga akhir semester pembelajaran remedial belum bisa membantu peserta didik mencapai KKM, pembelajaran remedial bagi peserta didik tersebut dapat dihentikan. Pendidik tidak dianjurkan memaksakan untuk memberi nilai tuntas (sesuai KKM) kepada peserta didik yang belum mencapai KKM. Namun berdasarkan data yang diperoleh peneliti menunjukkan bahwa setelah siswa mengikuti remedial nilai yang diperoleh langsung mencapai KKM tanpa guru mengoreksi tes 
remedial yang diberikan siswa karena guru disibukkan dengan kegiatan administrasi guru dan beban mengajar guru yang padat sehingga guru tidak sempat memeriksa hasil remedial siswa. Setelah siswa mengikuti remedial menunjukkan bahwa remedial dapat meningkatkan nilai hasil belajar siswa dari sebelumnya tidak mencapai KKM menjadi mencapai KKM. Meskipun nilai yang diperoleh siswa setelah mengikuti remedial hanya sebatas nilai KKM dan tidak melebihi nilai KKM. Hal ini sejalan dengan penelitian yang dilakukan oleh Bukhari (2017) dan Jangid dan Inda (2016) yang menunjukkan bahwa dengan pelaksanaan remedial dapat membantu siswa dalam meningkatkan nilai hasil belajar yang diperoleh siswa.

Penilaian yang diberikan guru bagi siswa yang mengikuti remedial sebatas nilai KKM saja, dengan tujuan nilai yang diperoleh siswa bersifat adil dan tidak memihak antara siswa yang mengikuti remedial dengan siswa yang tidak mengikuti remedial. Hasil penelitian tersebut sesuai menurut Kemendikbud (2017), tes remedial diberikan kepada peserta didik yang telah mengikuti program pembelajaran remedial, agar dapat diketahui pencapaian ketuntasan dalam penguasaan kompetensi yang telah ditentukan atau belum. Sementara nilai hasil remedial tidak melebihi nilai KKM.

\section{SIMPULAN DAN SARAN}

Berdasarkan hasil penelitian yang telah diuraikan di atas, dapat disimpulkan pelaksanaan pembelajaran remedial kimia di SMA Negeri 2 Singaraja belum seluruhnya mengikuti prosedur yang seharusnya dilakukan menurut petunjuk teknis pembelajaran tuntas, remedial, dan pengayaan di SMA dari Direktorat Pembina SMA diantaranya: (1) Perencanaan pengajaran remedial dilakukan guru kimia, yaitu guru menyusun program pengajaran remedial dengan menentukan waktu, metode dan tujuan pembelajaran remedial kimia, (2) pelaksanaan pembelajaran remedial kimia dilaksanakan pada penilaian harian $(\mathrm{PH})$ dan penilaian akhir tahun (PAT) dengan pemberian tugas kepada siswa berupa pengerjaan soal-sal pada LKS pegangan siswa atau pengerjaan kembali soal atau tes sebelumnya dan dikumpulkan tanpa pemberian materi ulang terkait indikator atau KD yang belum dipahami siswa, sedangkan pembelajaran remedial pada penilaian tengah semester (PTS) tidak dilaksanakan, dan (3) penilaian pembelajaran remedial yang dilakukan oleh guru kimia, yaitu dengan memperhatikan nilai KKM. Nilai yang diperoleh siswa setelah mengikuti remedial sebatas nilai KKM yang telah ditetapkan dengan tujuan agar nilai yang diperoleh siswa yang tidak mengikut remedial dengan siswa yang mengikuti kegaiatan remedial bersifat adil dan tidak memihak.

Berdasarkan hasil penelitian ini disampaikan beberapa saran sebagai berikut. (1) pada penyusunan program remedial guru seharusnya terbiasa melakukan analisis hasil penilaian harian, agar indikator soal yang tidak tuntas jelas terlihat dan guru dapat memilih strategi dan metode remedial yang paling tepat dalam pembelajaran remedial, (2) guru hendaknya mempersiapkan pembelajaran remedial layaknya pembelajaran reguler untuk dapat melaksanakan pembelajaran remedial dengan baik seperti membuat RPP, silabus dan lain-lain, (4) guru diharapkan mampu menerapkan serta melaksanakan remedial yang sesuai dengan konsep pembelajaran remedial yang mana pembelajaran remedial dapat dilakukan dengan cara menjelaskan kembali materi yang belum siswa mengerti dengan metode dan media pembelajaran yang lebih bervariasi sesuai dengan kebutuhan belajar masing-masing siswa, dan (4) melihat banyaknya masalah mengenai waktu yang tersedia bagi guru dan siswa untuk melaksanakan pembelajaran remedial yang sesuai dengan yang disarankan oleh Depdiknas, maka pihak sekolah perlu merevisi kembali pengelolaan waktu belajar.

\section{DAFTAR RUJUKAN}

Bukhari. (2017). Penerapan Pengajaran Remedial Terhadap Peningkatan Hasil Belajar Siswa Pada Pokok Bahasan Ikatan Ion dan Ikatan Kovalen. Jurnal Dedikasi Pendidikan, 1(1), $11-20$.

Chitsa, B. (2016). Remedial Education in Inclusive Secondary Schools in Zimbabwe: Implementaion, Constaints and Opprtunities. International Journal of Multidisciplinary Academic Research, 4(4), 8-14.

Direktorat Pembinaan SMA. (2010). Juknis Pembelajaran Tuntas, Remedial, dan Pengayaan di $S M A$. Jakarta: Direktorat Jenderal.

Direktur Jendral Pendidikan Dasar dan Menengah. (2017). Panduan Penilaian oleh Pendidik dan Satuan Pendidikan untuk Sekolah Menengah Atas. Jakarta: Kementerian Pendidikan dan Kebudayaan. 
Hermawati, H., Nurcahyono, N. A., \& Setiani, A. (2018). Proses Pelaksanaan Remedial Teaching Terhadap Ketuntasan Belajar Matematika Peserta Didik. Jurnal LP3M Universitas Sarjanawiyata Tamansiswa Yogyakarta, 4(2), 102-106.

Irnidayanti, Y., \& Puspitaningrum, R. (2013). Penerapan Program Remedial Dalam Pembelajaran Biologi di Sekolah Menengah Atas. Jurnal Pendidikan Universitas Jakarta, 27(2), 187192.

Jangid, N., \& Inda, U. S. (2016). Effectiveness of Remedial Teaching on Thinking Strategies of Slow Learners. International Journal of Indian Psychology, 4(1), 98-105.

Kasran, S. B., Toran, H., \& Anur, A. M. Issues and trends in remedial education: what do the teachers say?. Social and Behavioral Sciences, 47, 1597-1604.

Kurnia, R. (2016). Pelaksanaan Pembelajaran Remedial Pada Mata Pelajaran Matematika di Kelas II SDN 1 Sedayu. Jurnal Pendidikan Guru Sekolah Dasar, 01, 324-36.

Menteri Pendidikan dan Kebudayaan Republik Indonesia. (2013). Lampiran Permendikbud Nomor 81A Tahun 2013 Tentang Implementasi Kurikulum Pedoman Umum Pembelajaran. Jakarta: Kementerian Pendidikan dan Kebudayaan RI.

Syah, M. (2008). Psikologi Pendidikan dengan Pendekatan Baru. Bandung: PT. Remaja Rosdakarya.

Sugihartono, Fathiyah, K. N., Setiawati, F. A., \& Nurhayati, S. R. (2007). Psikologi Pendidikan. Yogyakarta: UNY Press.

Undang-Undang Republik Indonesia Nomor 20 Tahun 2003 Tentang Sistem Pendidikan Nasional. Jakarta: Departemen Pendidikan Nasional.

Qibtiyah, M., Wibowo, Y., \& Ratnawati. (2017). Pelaksanaan Program Remedial Pada Mata Pelajaran Biologi Kelas XI di SMA Negeri Se-Kabupaten Sleman. Jurnal Prodi Pendidikan Biologi, 02, 381-391. 